\title{
Closure of large post-endoscopic submucosal dissection defects with lateral mucosal incisions and clips
}

\author{
Georgios Mavrogenis ${ }^{a}$, loannis Tsevgas ${ }^{a}$, Georgia Dragini' ${ }^{b}$, Dimitrios Zachariadis ${ }^{a}$
}

Mediterraneo Hospital, Athens, Greece

With the introduction of endoscopic submucosal dissection (ESD) techniques, complex lesions can now be resected. Artificial ulcers may be closed or left open according to endoscopist's preference. However, closure of large defects may accelerate healing and thus diminish the risk of late bleeding [1]. Clipping of large defects in a sequential zipper fashion can be cumbersome or even impossible. Alternative options include the use of a double-channel endoscope with an endoloop and clips, a figure of 8-shaped stainless clip in combination with clips, a nylon-string loop attached to a clip, over-thescope clips and the overstitch endoscopic suturing device $[2,3]$. Nevertheless, these techniques need additional equipment and increase the overall cost. We recently had the experience of an 80 -year-old patient under low-dose aspirin with a history of chronic renal failure, who underwent ESD of a $3 \times 3 \mathrm{~cm}$ early gastric cancer (carcinoma in situ) (Fig. 1). The post-ESD defect was too large for clipping in a zipper fashion. We decided to apply a technique introduced by Otake et al [3], for the closure of colonic mucosal defects. Two small incisions were made in each side of the defect. These mucosal holes served as a grip for traction. With the help of two clips (Hemoclip, Life Partners, France), the oral border of the defect was dragged and then attached to the opposite border. Then, complementary closure of the residual defect was easily achieved with 7 additional clips (EZ Clips, Olympus, Greece). The patient was discharged after $24 \mathrm{~h}$, and did not present any complication.

Departments of a Gastroenterology (Georgios Mavrogenis, Ioannis Tsevgas, Dimitrios Zachariadis); ' Anesthesiology (Georgia Dragini), Mediterraneo Hospital, Athens, Greece

Conflict of Interest: None

Correspondence to: Georgios Mavrogenis, Kavetsou 10, 81132 Mytilene, Lesvos, Greece, Tel.: +30 22510 55557, Fax: +30 22510 42290, e-mail: mavrogenis@gmail.com

Received 10 April 2016; accepted 25 April 2016; published online 11 May 2016

DOI: http://dx.doi.org/10.20524/aog.2016.0043

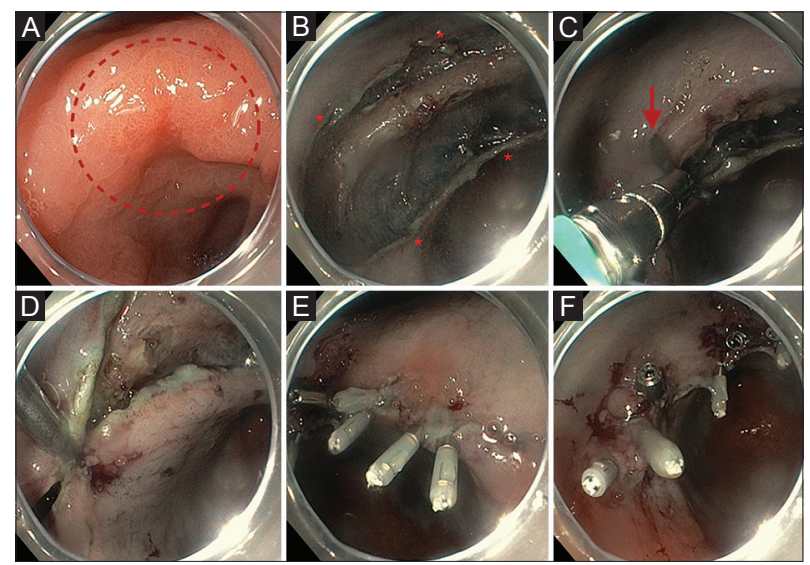

Figure 1 (A) Early gastric cancer of the angulus (Paris IIb+IIc, Tis). (B) Post-endoscopic submucosal dissection mucosal defect. Small incisions (holes) were made using a Dual Knife (Olympus) around the lateral borders (asterisks). (C) The extremity of the first clip was 'anchored' into the hole (arrow) and the mucosal border was dragged towards the opposite mucosal border. (D) The other arm of the clip was inserted into the opposite hole and then it was deployed. (E, F) After placement of two clips using the aforementioned method, the remaining gap was clipped in a conventional zipper fashion

\section{References}

1. Kim DS, Jung Y, Rhee HS, et al. Usefulness of the Forrest classification to predict artificial ulcer rebleeding during secondlook endoscopy after endoscopic submucosal dissection. Clin Endosc 2016 [Epub ahead of print].

2. Fujii T, Ono A, Fu KI. A novel endoscopic suturing technique using a specially designed so-called "8-ring" in combination with resolution clips (with videos). Gastrointest Endosc 2007;66:12151220.

3. Otake Y, Saito Y, Sakamoto T, et al. New closure technique for large mucosal defects after endoscopic submucosal dissection of colorectal tumors (with video). Gastrointest Endosc 2012;75:663-667. 